\title{
仮想液体操作における密度変化モデルによる流れの表現
}

\section{Expression of Liquid Flow with Density Change Model in Virtual Liquid Manipulation}

\author{
舟橋健司 $* 1$ 宇佐美健一 $* 2$ 岩堀祐之 $* 3$ \\ Kenji Funahashi*1, Ken-ichi Usami*2 and Yuji Iwahori*3 \\ *1,*3 名古屋工業大学 情報メディア教育センター＊2 株式会社 メイテッコム \\ *1,*3Nagoya Institute of Technology and ${ }^{* 2}$ MEITETSU COM Co.,Ltd. \\ *1 kenji@center.nitech.ac.jp
}

アブストラクト：本論文では新たな液体の表現モデルについて検討する。従来、液体などの挙動シ ミュレーションやアニメーションに関する研究は多く行われている。しかし、これまでに仮想的な操 作を考慮したものはない。本モデルは挙動を厳密に再現するものではなく、実際の挙動の特徵をリア ルタイムに表現するものである。我々はこれまでに、液体を静止状態と自由落下状態に分類すること により、落下して来る液体を容器により受け止め、また他の容器からすくいとり、容器を傾けること によりこぼすという対話的な操作を可能とした。さらに流れの状態の液体を扱うために、液体を扱う 容器を格子状に区切り、各格子に対する液体の密度と平均速度を定義する。これらの值を隣接する格 子の状態に応じて変更していくことにより、対話操作可能な状態として液体の流れの状態を表現す る。実験システムでは、容器を緩やかに傾けることにより、液体の流れの表現が可能である。

Abstract: In this paper, a model to realize an interactive manipulation of virtual liquid using a virtual vessel is described first. Then, we extend this model for the liquid flow. We consider that a liquid vessel is separated into a grid and define the density and the average velocity of liquid in each grid. We decide the movement of a liquid using these value, then we can realize an interactive manipulation of the flowing liquid. Our system with this proposed model makes it possible to catch the liquid, then to flow and spill the liquid by tilting it.

キーワード：仮想液体、対話操作、液体容器、液体の流れ、密度変化モデル

Keywords: virtual liquid, interactive manipulation, liquid vessel, liquid flow, density change model 


\section{1 はじめに}

現在では, バーチャルリアリティ(VR) 技術は工学分 野のみならず, アミューズメント, エンターテイメント やアート分野などにおいても研究が行われている.VR 技術に対する要望のひとつとして仮想空間中における 対話操作, というものがある. 従来は主に, 仮想空間に 存在する固体 (岡体や弾性体) を対話的に移動, 変形す る研究が行われて来た $[1,2]$. しかし, 医療やアートの分 野などにおいて固体だけでなく, 液体や気体に対しても 仮想空間で対話操作が行えれば，より高い応用性が期 待できる.

液体や気体の流れを扱った学問としては流体力学が 挙げられる.これは液体などの挙動を厳密に計算する には適しているが, 計算量が多いため, リアルタイム処 理を行う必要がある対話操作には直接適用することは 出来ない. また, コンピュータグラフィックス $(\mathrm{CG})$ や VR の分野においても液体, 気体に関する研究は行われ ている [3-5]. これらの研究も, 主にリアリティの高い CG を作成することを目的としており対話操作には向 いていない. Stam は流体アニメーション作成の高速な 手法を提案している [6]. Navier-Stokes 方程式をもと に, テクスチャマッピングを利用しているこの手法は, 対話的にアニメーションを作成可能である. しかし, 入 れ物を用いた液体に対する,すくう,こぼす等の操作へ の直接的な適用は難しい.

我々はこれまでに, 仮想空間における任意な形状の容 器による液体の対話操作を実現する新たな仮想液体操 作モデルを提案している [7-9]. このモデルでは仮想空 間内に液体との干渉を判定すべき仮想の容器を定義し， 容器と液体との相互作用についてのみ考え, 以下のよ うな動作を可能としている.

・落下して来る液体を容器で受け止める

・容器内の液体を別の容器ですくいとる

・容器から液体を落下させる

本研究では,このモデルを拡張することにより, 流れ の状態にある仮想液体の表現手法の提案を行う $[10,11]$. 本手法では流れている状態の仮想液体を粒子に基づい て表現する. 粒子個々の挙動を追うのではなく,一定領 域内にある液体粒子の密度と平均速度を定義する. 光し てこの 2 つの值を隣接する格子間で变化させる事によ り液体の移動を表現する.なお, このモデルは対話操作 を第一の目的としたものであり, 挙動の厳密な再現を 主な目的とはしていない. CG によるリアリティの高 い映像のリアルタイム生成は, 今後の課題としたい.

\section{2 粒子体積に基づくモデル}

本節では,これまでに提案した任意形状の容器による 液体の対話操作を実現するための仮想容器, および, 仮 想液体のモデルについて述べる.

このモデルでは液体を以下の 2 つの状態で考える.

○自由落下 現実では, 空から降って来る雨, 水道の蛇 口から流れ落ちる水などがある.ここでは, 液体を粒子 に基づき表現する. 本研究では微妙な動きよりも対話操 作を目的としているため, 各粒子は大きさを考えないも のとする. また, 粒子同士の干渉は起こらず, 2 つの粒子 が衝突して 1 つになるという現象も起こらないものと する. これらの粒子は重力と慣性によって移動する.

○静止状態 現実では, コップの中の水などがある.こ こでは, 容器内の対流などを考えず, 完全に静止した液 体として扱い, 体積により表現する.すなわち, ある時 刻 $t$ において液体が仮想空間内の容器に存在している 場合, 上述の粒子の性質は一切考慮せず, 容器の中に体 積 $V(t)$ の液体が存在していると表現する.

上記の 2 状態間の換算には換算比 $N[$ 粒子数 $/$ 体積 $]$ を 用いる. 仮に容器内に体積 $V$ の静止状態の水があると して, 光の全体積をこぼすと $N V$ 個の粒子と体積 0 の 静止状態の水となる. このモデルに基づき作成した実 験システムでは, 落下してくる液体を操作者が自由に動 かすことのできる仮想の容器で受け止め, 容器の中に溜 めることが可能である. また, 操作者が容器を傾けるこ とにより, 容器内の液体をこぼすことも可能である.さ らに, 他の容器内の液体をすくう操作も可能である. 相 対的静止状態など,詳しくは文献 [7-9] を参照されたい.

\section{3 密度変化モデル}

\section{1 液体の流れの表現方法}

流れている状態の液体は現実では, 川の水や雨樋を流 れる水などがある. 液体を粒子に基づく方法で表現し ようと考えた場合 (図 1 左), 液体粒子关れ攵れの位置 や速度をもとに全体の液体の挙動を考える必要があり, 計算量が多くなる. 兴のため, リアルタイム処理を考え る際には個々の液体粒子の挙動を考えるという手法を 直接用いることはできない.

乥こで, 前述した 2 つの状態の中間的な状態を考え る. まず液体の流れを考慮する部分を予め格子状に区 切っておく.この格子内の液体粒子乥れ光れの挙動を 見るかわりに, この領域内では液体粒子が一樣に分布し 


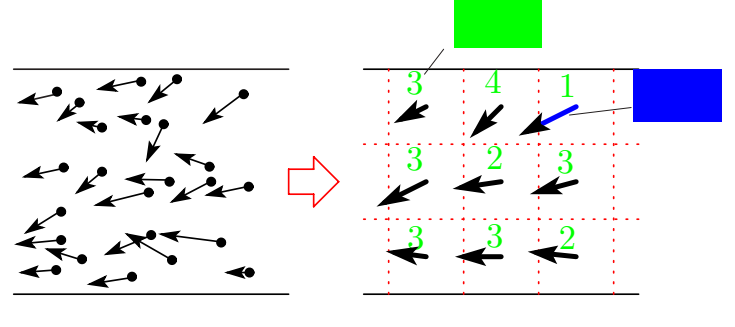

図 1: 流れている液体のモデル

ていると仮定して,一定領域内に含まれる液体粒子の個 数, つまり液体の密度と平均速度を考える (図 1 右). こ の 2 つの值を隣接する格子間で変化させることによっ て液体の流れを表現する.

\section{2 容器のモデル}

以下では容器内における液体の流れを考える. 液体 の流れを考える容器 (以下, 単に容器と呼ぶ) を予め一 辺の長さが $d$, 容積 $d^{3}$ の格子状に区切っておく. 乥し て区切られた格子光れ光れについて, 液体の平均速度 を $\mathbf{v}$, 格子内にある液体粒子の密度を $D$ [粒子数/容積] と定義する. この速度と密度を隣接する格子間で变化 させるという処理を繰り返し行うことにより,全体的に 見れば液体が流れているような動作を実現する. 多く の液体は気体のように圧縮されることはないため, 液 面付近以外では液体粒子の密度は一定になるはずであ る (このときの液体の密度を $N$ と定義する, 格子内の 液体の粒子数は $N d^{3}$ である). しかし, 本手法では液体 を隣接する格子間で夜体を漸次移動させる方法である ため,一時的に液体粒子の密度 $D$ が一定の範囲内で増 減することを認める.

\section{3 処理の流れ}

ある時刻 $t$ における状態から $t+\Delta t$ の状態を求める には以下に示す処理を行う. 兴の処理を繰り返し行う ことにより液体の流れを表現する. 以降, 弚れ光れの処 理について説明する。

(1) 密度の変化の実行

(1.a) 各格子内の密度の変化量の計算 まず始めに, 時 刻 $t$ から $t+\Delta t$ に状態が変化する際に各格子から他 の格子へ移動する液体の粒子数を計算する. 考え方は, 格子内に一樣分布している液体粒子を平均速度分だけ 移動させる, というものである. 時刻 $t$ において, 座標 $(i, j, k)$ の位置にある格子 $L^{(i, j, k)}$ 内の液体粒子の密度
を $D(t)^{(i, j, k)}$, 平均速度を $\mathbf{v}(t)^{(i, j, k)}$ と定義した時, 移動 する液体の密度は以下の処理を行うことにより求まる. step1 立方体の想定 格子 $L^{(i, j, k)}$ 内の液体か密度 $N$ で あつたときの体積は $\frac{D(t)^{(i, j, k)} d^{3}}{N}$ であらわせる. 次に, 格 子 $L^{(i, j, k)}$ と重心が同じ座標にあり, 体積が $\frac{D(t)^{(i, j, k)} d^{3}}{N}$ の立方体を定義する (図 2 (a) 点線部分). この立方体は 格子内にある液体を想定するものである.これを次のス テップ以降で変形, 移動した後の位置を基準に $L^{(i, j, k)}$ から隣接する格子に移動する液体の量を決定していく. なお, 簡単のために 2 次元の図で表現しているが, 実際 の処理は 3 次元で行う.

step2 圧力を考慮した形状の変形 注目している格子 内の液体密度に対して隣接格子内の液体密度が高い場 合, 圧力により注目格子の外へ移動する液体は少なく なる. 逆に注目格子に対して隣接格子内の液体密度が 低い場合には外へ移動する液体は多くなる.このこと を考慮し step1 で求めた立方体の形状を変形する. 立 方体の各面の変化量は $D(t)^{(i, j, k)}$ と, 周囲の格子内の 液体の密度 $D(t)^{(i+p, j+q, k+r)}$ (ただし,step2 において は $(p, q, r)=(-1,0,0),(1,0,0),(0,-1,0),(0,1,0)$, $(0,0,-1),(0,0,1)$ の, 面で隣接する 6 通り) を兴れ艺 れ比較し, 光の差に比例する距離 $m_{(i, j, k)}^{(p, q, r)}$ だけ立方体の 各面の位置を変化させる (図 2(b) 破線部分).

$$
\begin{gathered}
m_{(i, j, k)}^{(p, q, r)}=\rho\left(D(t)^{(i, j, k)}-D(t)^{(i+p, j+q, k+r)}\right) \\
\rho: \text { 比例定数 }
\end{gathered}
$$

step3 直方体の移動 次に step2 によって変形された 直方体を格子内の液体の平均速度 $\mathbf{v}(t)^{(i, j, k)}$ を用いて 移動させる (図 2(c) 太線部分). これは時刻 $t$ において 格子 $L^{(i, j, k)}$ にあった液体が流れる樣子を表している. 直方体の移動距離は $\Delta t \mathbf{v}(t)^{(i, j, k)}$ で表せる.

step4 移動する密度の計算 step3 の処理により移動 した直方体が, どの格子の中にどれだけの割合で含ま れているかを計算する. この割合が, $L^{(i, j, k)}$ から移動 する液体 (粒子) の割合となる. 直方体のうち, $L^{(i, j, k)}$

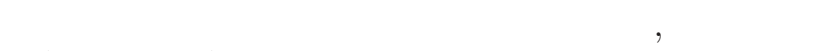
$B_{(i, j, k)}^{(i+p, j+q, k+r)}$ とする(図 $2(\mathrm{~d})$ 斜線部分). ただし, step4 においては $p, q, r$ のとる值は光れ光れ $-1,0,1$ のいず れかである. 直方体のうち, 格子 $L^{(i, j, k)}$ の内部に含ま れている部分の体積は $B_{(i, j, k)}^{(i, j, k)}$ であらわせる. このよう においた時, $L^{(i, j, k)}$ から単位体積の格子 $L^{(i+p, j+q, k+r)}$ に移動する液体の粒子数 $T_{(i, j, k)}^{(i+p, j+q, k+r)}$ は以下の式で 求まる. 他の格子へ移動せず元の格子に留まる液体は 


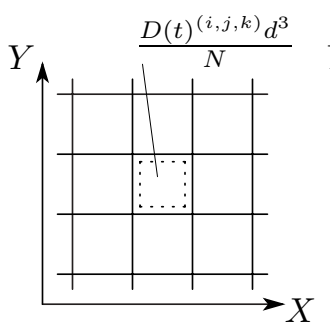

(a)

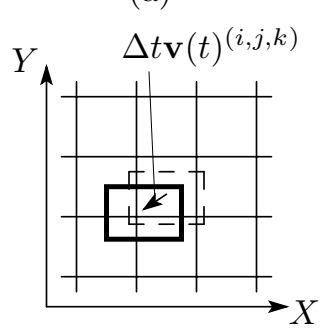

(c)

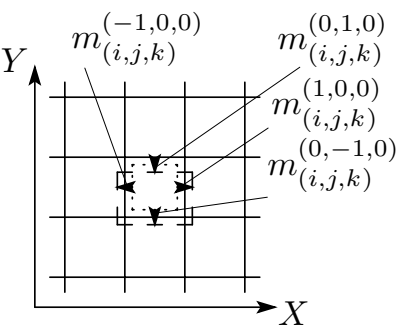

(b)

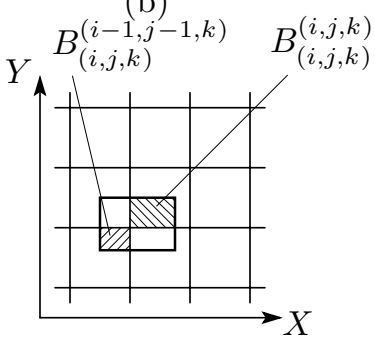

(d)
図 2: 格子内密度の変更量の計算

$T_{(i, j, k)}^{(i, j, k)}$, すなわち $p=q=r=0$ により求まる.

$T_{(i, j, k)}^{(i+p, j+q, k+r)}=D(t)^{(i, j, k)} \frac{B_{(i, j, k)}^{(i+p, j+q, k+r)}}{\sum_{u, v, w=-1}^{1} B_{(i, j, k)}^{(i+u, j+v, k+w)}}$

ただし, 液体の移動先の格子内の密度か設定されたしき い値よりも高い場合は, 兴の格子へ液体力移動して更に 密度が高くなるのを防ぐために, $B_{(i, j, k)}^{(i+p, j+q, k+r)}=0$ と して計算する. また, 直方体の移動先が容器の壁面より も外部に出てしまった場合も同樣に $B_{(i, j, k)}^{(i+p, j+q, k+r)}=0$ として計算する.

以上の step1 から step4 までの処理を全ての格子につ いて行うことにより, 液体の移動量を計算する.

(1.b) 全格子の液体密度の変更 前述の方法により各 格子について密度の変化量を計算した後, 全ての格子 の密度を更新する. ある格子 $L^{(i, j, k)}$ に注目した時, 液 体を移動させた後の密度は次式で示される.

$$
D(t+\Delta t)^{(i, j, k)}=\sum_{p, q, r=-1}^{1} T_{(i+p, j+q, k+r)}^{(i, j, k)}
$$

(2) 速度の変更

(2.a) 密度の変化に伴う速度の変更 密度の更新を行っ たことに伴い, 各格子内の液体の平均速度も変更する 必要がある. ある格子 $L^{(i, j, k)}$ において, 密度の更新を 行った後の平均速度 $\mathbf{v}(t)_{T}^{(i, j, k)}$ は以下の通りである.

$$
\mathbf{v}_{T}=\frac{\sum_{u, v, w=-1}^{1} \mathbf{v}(t)^{(i+u, j+v, k+w)} T_{(i+u, j+v, k+w)}^{(i, j, k)}}{\sum_{p, q, r=-1}^{1} T_{(i+p, j+q, k+r)}^{(i, j, k)}}
$$

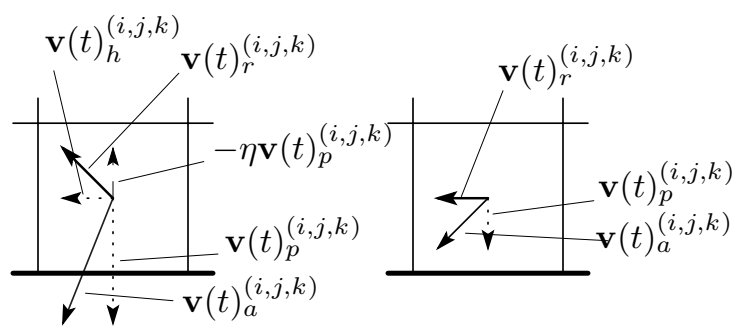

(a)

(b)

図 3: 壁面部分における液体の反射

(2.b) 液体の加速 液体の流れを考えている容器が移 動する際, 容器内の液体は元の位置に留まろうとするの で, 容器に加えられた力とは逆向きに反作用の力がかか る. 時刻 $t$ における容器の中央の座標を $\mathbf{C}(t)$ とする と, 液体にかかる加速度 $\mathbf{a}(t)$ は

$$
\mathbf{a}(t)=-\frac{\mathbf{C}(t)-2 \mathbf{C}(t-\Delta t)+\mathbf{C}(t-2 \Delta t)}{\Delta t^{2}}
$$

である.また, 液体には常に重力加速度 $\mathrm{G}$ がかかって いる. これらにより, 格子 $L^{(i, j, k)}$ 内の液体の速度は以 下のようになる.

$$
\mathbf{v}(t)_{a}^{(i, j, k)}=\mathbf{v}(t)_{T}+\Delta t \mathbf{G}+\Delta t \mathbf{a}(t)
$$

(3) 例外処理

(3.a) 壁面における液体の反射 容器の壁面 (底面) 部 分においては, 液体の速度の壁面に垂直な方向成分は反 対方向へ反射する. 本手法では液体を減衰率 $\eta$ で非弾 性衝突させる (図 3(a)).ただし振動を抑制するために, 壁面に対して垂直な方向の速度成分が一定のしきい值 $\mathrm{f}$ 以下の時は反射は行わず, 垂直方向の成分を 0 とする (図 3(b)). 格子 $L^{(i, j, k)}$ の速度が $\mathbf{v}(t)_{a}^{(i, j, k)}$ の時, 壁面 に対して垂直な方向の速度成分を $\mathbf{v}(t)_{p}^{(i, j, k)}$, 平行な方 向の成分を $\mathbf{v}(t)_{h}^{(i, j, k)}$ とすると, 壁面での反射を考慮し た後の速度 $\mathbf{v}(t)_{r}^{(i, j, k)}$ は以下のようになる。

$$
\mathbf{v}_{r}= \begin{cases}\mathbf{v}(t)_{h}^{(i, j, k)}-\eta \mathbf{v}(t)_{p}^{(i, j, k)} & \left(\mathrm{f}<\mathbf{v}(t)_{p}^{(i, j, k)}\right) \\ \mathbf{v}(t)_{h}^{(i, j, k)} & \left(\mathrm{f} \geq \mathbf{v}(t)_{p}^{(i, j, k)}\right) \\ \mathbf{v}(t)_{a}^{(i, j, k)} & (\text { 壁面以外) }\end{cases}
$$

(3.b) 容器の底面付近での処理 容器の底面付近の格 子では, 重力により下向きの速度をもつた液体が常に流 れ込んでくる. 谷のため, 密度が高い状態力続いてしま い, 時間か経過しても容器内の液体の密度は均等には成 らないという状況が生じる. この問題を改善するため, 容器の底面の方では例外的な処理を行う。

条件 1：格子内の密度がしきい值より大きい.

条件 2: 格子の下方 3 方向が容器の壁面であるか, こ 
こで示す例外処理が行われている状態であり，下方へ と液体が流れてはいけない状況である.

条件 3: 1,2 を満たす状況が一定時間継続している.

以上の条件を満足した格子について, 格子の各面を容 器の壁面と同樣の扱いにする. つまり, 隣接する他の格 子からこの格子へ移動してこようとしてくる液体につ いては, 移動させず, 平均速度についてはこの格子の面 に垂直な方向に反射させる. ただし, この格子から他の 格子へ移動する液体については通常どおり移動させる. このような処理を条件 1,2 を満たさなくなるまでの間, つまり格子内の密度が一定值以下になるか, 下方へと液 体が流れて行ける状態になるまで続ける.

(3.c) 速度の制限 最後に, 液体の速度か限界值を超え ないように調整を行う.このモデルでは速度 $\mathbf{v}$ は一定 速度 $\left|\mathbf{v}_{\max }\right|$ 以上にはならないものとしている. これは $\mathrm{v}$ が大きくなりすぎると, 単位時間の間に隣接する格子 よりも遠方まで夜体が移動することを考慮する必要が あるためである.つまり, 液体の最高速度 $\left|\mathbf{v}_{\text {max }}\right|$ は時 間 $\Delta t$ の間に格子の 1 辺の長さ $d$ だけ進む速度とする. 格子 $L^{(i, j, k)}$ の速度が $\mathbf{v}(t)_{r}^{(i, j, k)}$ の時, 調整をおこなつ た後の速度 $\mathbf{v}(t+\Delta t)^{(i, j, k)}$ は次式で表せる.

$$
\mathbf{v}= \begin{cases}\mathbf{v}(t)_{r}^{(i, j, k)} \frac{\left|\mathbf{v}_{\max }\right|}{\left|\mathbf{v}(t)_{r}^{(i, j, k)}\right|} & \left(\left|\mathbf{v}(t)_{r}^{(i, j, k)}\right|>\left|\mathbf{v}_{\max }\right|\right) \\ \mathbf{v}(t)_{r}^{(i, j, k)} & \left(\left|\mathbf{v}(t)_{r}^{(i, j, k)}\right| \leq\left|\mathbf{v}_{\max }\right|\right)\end{cases}
$$

容器の大きさを考慮して格子の大きさを設定すること により，一般に扱う液体に関しては問題は小さいと考 えられる.

\section{4 自由落下状態の液体と容器}

ここでは自由落下状態の液体が容器に入り, 流れの状 態になる時, 逆に流れの状態から自由落下状態の液体に なる時の遷移モデルについて説明する.

自由落下状態から流れの状態へ 自由落下状態の液体 (ある粒子) が容器の内部にあった場合, 谷の液体を粒子 としては消滅させ, 乥の粒子の存在した座標を含む格 子内の液体の密度を増加させる. また速度の更新時に 粒子の最終速度を考慮する.

流れの状態から自由落下状態へ 容器の口を構成する 格子内の液体の移動先が, 容器の外部であった場合, 移 動した液体の密度に比例した量だけ自由落下状態の粒 子を作成する.

\section{4 実験および結果}

上述のモデルに基づいた仮想液体操作のための実験 システムを,グラフィックワークステーション SGI OCTANE2 上で $\mathrm{C}$ 言語により実現した．液体の流れを考 える仮想容器は操作者が自由に移動することが可能で, 容器の位置と傾きは低周波の磁界を利用したモーショ ンセンサにより入力される. 液体の流れを考慮する容 器の形状は縦横 $20 \mathrm{~cm}$, 高さ $6 \mathrm{~cm}$ を想定している. ま た, 格子の一辺の長さは $1 \mathrm{~cm}$, 容積 $1 \mathrm{cc}$ とする. 液体粒 子は 1 個 $0.1 \mathrm{cc}$ として扱う, すなわち換算比 $N=10$ [粒 子数/cc]である. 限られた画面内で実験を行うために, 重力加速度を $1 \mathrm{~m} / \mathrm{s}^{2}$ に設定する.

描画方法に関しては次の通りである. 2 節で述べた静 止状態の液体は水平面である液面を半透明表示し, 相 対的静止状態の液体の液面も平面として半透明表示す る. 自由落下状態の液体は, 粒子を小さな正方形として 半透明表示しており, 流れの状態にある液体は, 格子内 の液体密度から液面の位置を計算し, 液体の深さから 半透明の係数を決定してポリゴン表示している.

本システムを使用して実際に操作している例を 図 4 に示す.体験者がセンサの取り付けられたカップを操作 することにより，仮想容器で仮想液体を操作可能なこ とがわかる. 操作時の画面全体は図 5 に示す通りであ る. この時, 描画更新速度は毎秒 20 frame 程度であっ た. 対話操作においては一般に, ユーザがカップの移動 などを行ってから 10-12fps 程度で光の結果が反映され れば, ユーザは自身において映像中の操作を行ったと認 識すると言われている.

次に, 液体の流れを考えている容器をすこし左側に傾 けた時の樣子を連続画像として 図 6 に示す. 容器を傾 けたことによって液体が左側へと流れて行き, 容器から 外に出た液体が自由落下状態の粒子となっている. 液 体が少ない時の樣子を同樣に 図 7 に示す.ここでは容 器が左手前方向に傾いていて, 少量の液体が溜まってい る状態から容器を右奥方向に傾けた時の液体の動作を 示している. 左前方に溜まっていた液体が広がりなが ら流れて行き, 最終的に右奥方向に向かっていく樣子 が分かる.

実際に研究室内の数名の学生に体験実験をしてもらつ たところ, 本当に液体を扱っているように感じる, 液体 が流れているように見える,などといった積極的な意見 を頂いた．また計算機科学分野を専門としない学生に 対して, 詳細な説明無しに入力装置としてのカップを渡 したところ, 自身の動作に対する画面の変化から状況を 
把握し, 自由に液体の操作を行うことが可能であった. このモデルの現状の問題点としては,液体の量が少な い時, 液面が完全に水平にはならない, ということが挙 げられる. 例として, 容器の底面が水平方向と平行で, 容 器の底面にある格子内の液体の密度が低く, 各格子内の 液体の速度が全て 0 であるような状況を仮定する.こ の時, 密度变化を考える際に使用する直方体 (図 2(c) の 太線部分にあたる直方体) がもとの格子の内部に含ま れてしまい, この格子内の液体は他の格子へ移らない. そのため, 液面が水平にならない状態のままで安定して しまうという問題が存在する.

\section{5 むすび}

仮想空間における流れの状態にある液体の表現を, 液 体の流れを考える容器を格子状に区切り, 局所的に一 樣に分布する粒子を想定した密度変化モデルを用いて 実現した.本システムでは容器を傾けることによって流 れている状態の液体を自由に操作することができ,さら に自由落下してくる液体を受け止めること, 逆に流れて いる状態から液体をこぼして自由落下状態にすること も可能である.

実験システムにより, 密度変化モデルが操作を対象と した液体の流れの表現に有効であることが確認できた. 本モデルは液体の厳密な挙動の再現を目的としたもの ではないため, 全ての用途に応用できるものではない. 作業手順の確認や学習,インタラクティブアートのよう な「水の存在」自体が意義のある目的への応用が期待 できる.

今後の課題として, 前述の液面が完全に水平にはなら ない問題に対応する必要がある. 静止画では確認が困 難であるが, 流れの状態における粒子の分布が速やか に収束せず過渡的に液面が不自然になる場合もあるた め, この問題を解決する必要もある.

本システムでは経験的に設定した格子の大きさや液 体の粒子との換算比, 時間間隔 $\Delta t$ に関しても, 実験, 考 察しなければならない.これらはハードウェア技術の 進歩に伴う計算時間の短縮も考慮して検討したい。 た実際の液体では, 非圧縮性流体の場合には, 圧力は密 度, 重力と深さの積により考えることができる. 運動と 位置, 圧力により伝えられるエネルギーを考慮し, 物理 法則に基づくパラメータを導入した新たなモデルへと 発展させることにより，さらに自然な流れを表現する 必要がある. アート等の分野への応用を考えた場合, 液
体の挙動を考慮するだけでなく, 付加的な臨場感を高め る必要もある.CG による表現方法の向上や波の音な どの表現についても取り組んでいきたい.

謝辞

最後に, 本研究を進めるにあたり有益な議論を頂いた 本研究室諸氏, および卒業生に感謝する.なお, 本研究 の一部は名古屋工業大学研究活性化経費による.

\section{参考文献}

[1] 舟橋健司, 安田孝美, 横井茂樹, 鳥脇純一郎: “仮想空 間における仮想手による道具操作のための知識とモデ ル”, 日本バーチャルリアリティ学会論文誌, Vol.3, No.3, pp.167-176 (1998)

[2] 藤本英雄, 佐野明人, 磯部玄, 胡摩心一郎, 竹内博良: “マ イクロドームシステムを用いた力覚縫合シミュレータ”, SICE SI2001 講演論文集, pp.405-406 (2001)

[3] Michael Kass, Gavin Miller: "Rapid, Stable Fluid Dynamics for Computer Graphics," Proc. SIGGRAPH 90, pp.49-57 (1990)

[4] N. Chiba, S. Sanakanishi, K. Yokoyama, I. Ootawara: "Visual Simulation of Water Currents Using a Paticlebased Behavioural Model," The Journal of Visualization and Computer Animation, Vol.6, pp155-171 (1995)

[5] Jim X. Chen, Niels da Vitoria Lobo, Charles E. Hughes, J. Michael Moshell: "Real-Time Fluid Simulation in a Dynamic Virtual Environment," IEEE CG\&A, Vol.17, No.3, pp.52-61 (1997)

[6] Jos Stam: "Stable Fluids," Proc. SIGGRAPH 99, pp.121-128 (1999)

[7] 舟橋 健司, 岩堀 祐之: “仮想容器による仮想液体の対話 操作モデルと一実現法”, 日本バーチャルリアリティ学 会論文誌, Vol.5, No.4,pp.1087-1094 (2000)

[8] Kenji Funahashi, Yuji Iwahori: "Virtual Liquid Manipulation Using General Shape Vessel," Proc. IEEE VR2001, pp.283-284 (2001)

[9] Kenji Funahashi, Yuji Iwahori: "Representation of Swinging Liquid on Virtual Liquid Manipulation," Proc. ICAT2001, pp.179-184 (2001)

[10] 宇佐美健一, 舟橋健司, 岩堀祐之, 岩田彰: “格子モデル を用いた流れる液体に対する対話操作の検討”, SICE SI2001 講演論文集, pp.403-404 (2001)

[11] 舟橋健司, 宇佐美健一, 岩堀祐之: “仮想液体操作 - 密度 変化モデルによる流れの表現”, 第 18 回 NICOGRAPH 論文コンテスト論文集, pp.9-14 (2002) 


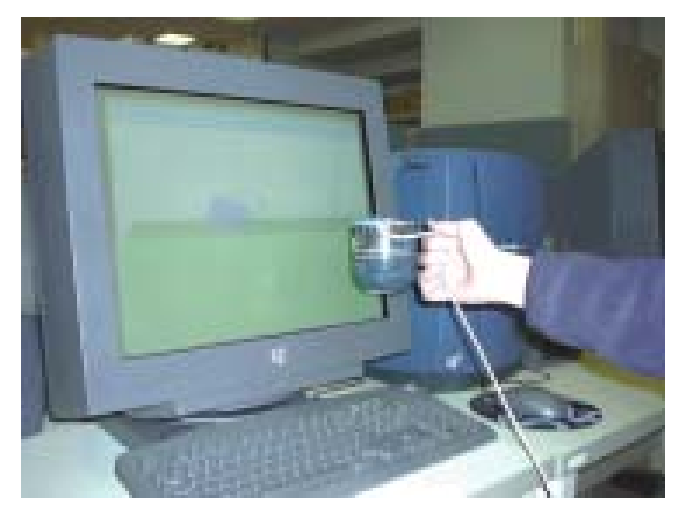

図 4: 実際の操作の樣子
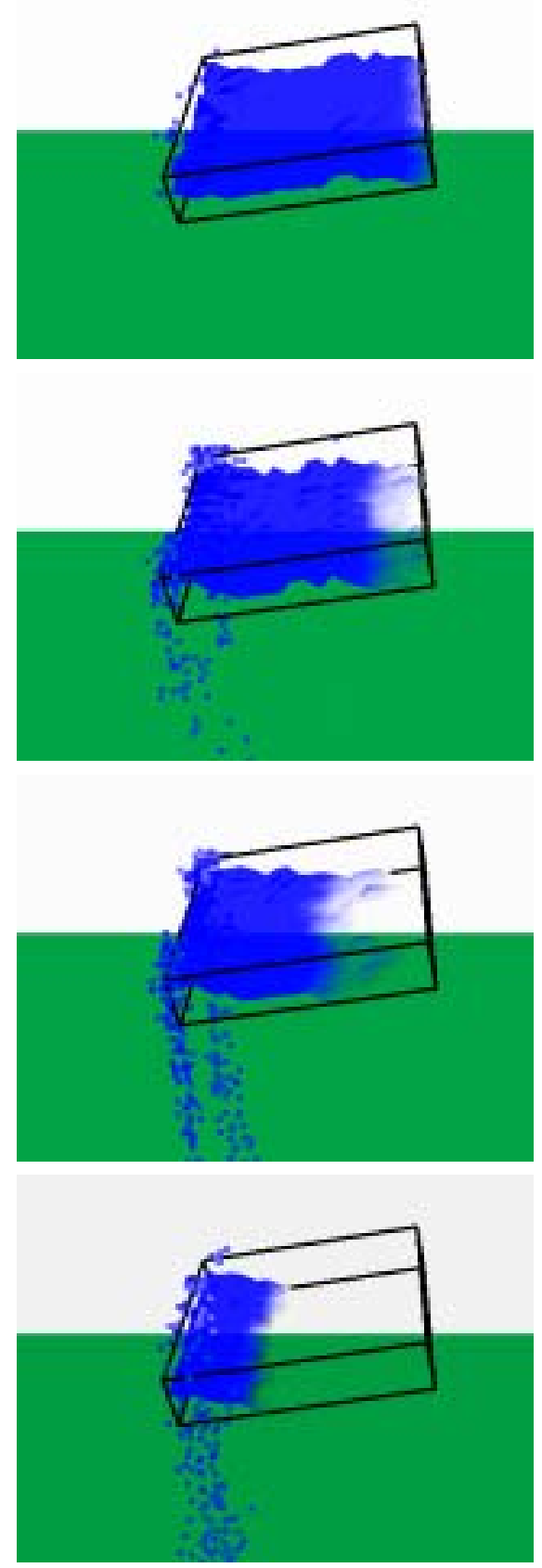

図 6: 実験結果の連続画像

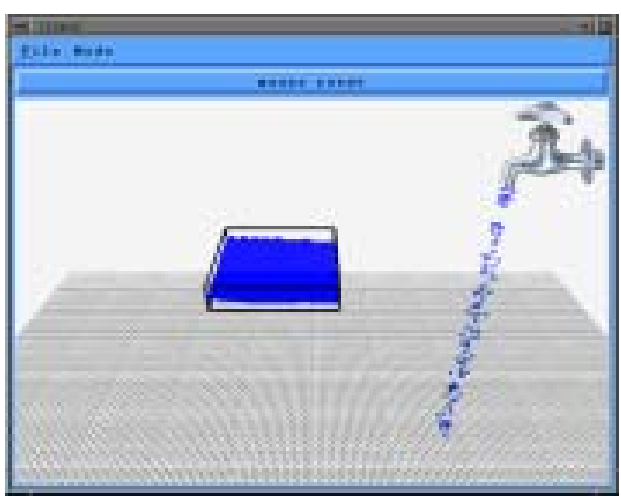

図 5: 操作時の画面表示
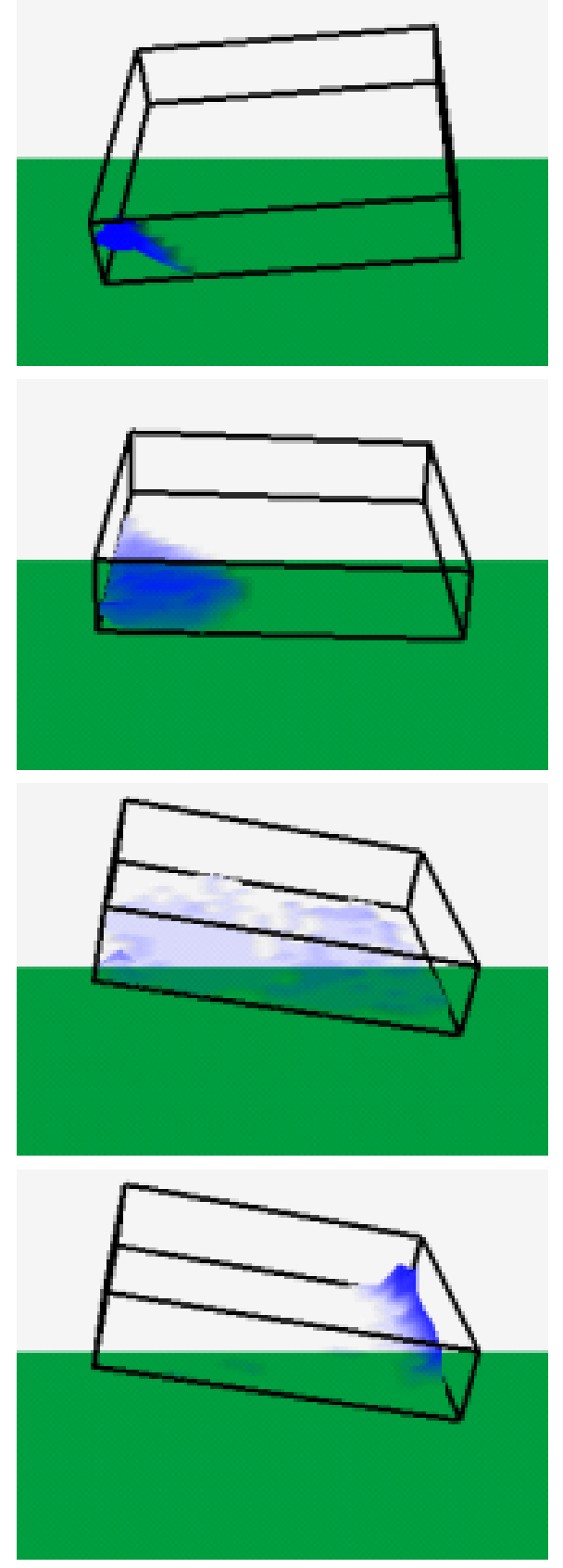

図 7: 液体が少ないときの動作 